\title{
Metodologia para avaliação do desgaste em ferramentas simétricas de mobilização do solo
}

\author{
Antônio L. T. Machado ${ }^{1}$, Amauri C. Espírito Santo ${ }^{2}$, Vilson J. Batista ${ }^{3}$, Ângelo V. dos Reis ${ }^{1}, 0$ toniel G. L. Ferreira ${ }^{1}$ \& André 0 Idoni $^{1}$
}

\section{RESUMO}

A correta avaliação e previsão do tempo de vida útil dos mecanismos que atuam no rompimento do solo, são importantes na análise de equipamentos. 0 desgaste deste tipo de ferramenta (ponteiras sulcadoras de semeadoras, de escarificadores e de subsoladores) depende de vários fatores, entre eles as condições do solo e características geométricas e construtivas das ferramentas. A taxa de desgaste das ferramentas de mobilização do solo, normalmente é determinada através da sua perda de massa. 0 objetivo do trabalho foi desenvolver uma metodologia diferenciada, ágil e de fácil execução, para avaliação do desgaste de ferramentas simétricas que promovem a mobilização do solo. A análise da variação da configuração geométrica da ferramenta foi obtida por fotografia digital utilizando-se, posteriormente, um programa computacional para o seu desenho. Utilizaram-se ponteiras sulcadoras de adubo de semeadora de plantio direto como ferramenta de mobilização de solo. $0 \mathrm{~s}$ resultados possibilitaram verificar que o desgaste é melhor determinado pelo método da fotografia digital que pelo método tradicional (perda de massa). A vantagem do método proposto reside basicamente em sua agilidade e precisão.

Palavras-chave: rompimento do solo, abrasão, fotografia digital

\section{Methodology for assessment of wear rate in symmetrical soil-engaging tools}

\begin{abstract}
The correct evaluation and prediction of the durability of soil-engaging mechanisms are important factors in the analysis of the agricultural equipments. The wear of these tools (planters furrow openers, chisel and subsoiler rippers) is dependent on various factors, among them the soil conditions and the geometric and constructive characteristics of the tool. The wear rate of the soil-engaging tools is usually determined through loss of mass. The analysis of the variation of the geometric configuration of the tool was assessed through digital photography, afterwards a software was used to design them. The objective of the study was to use a differentiated, agile methodology of easy execution, for evaluation of the wear of soil-engaging tools. In this study furrow openers of a direct drill planter was employed as the soil-engaging tool. The results show that the wear is best determined by the digital photography than the traditional method (loss of mass). The advantage of the proposed method consists basically in its agil ity and precision.
\end{abstract}

Key words: soil failure, abrasion, digital photograph

\footnotetext{
${ }^{1}$ DER/U FPel, Campus Universitário, CP 354, CEP 96010-900, Pelotas, RS. Fone: (53) 3275-7126, Fax: (53) 3275-9031. E-mail: lilles@ufpel.edu.br; areis@ufpel.edu.br; otoniel@ufpel.edu.br; andreoldoni@gmail.com

2 DEA/UFPel, Fone: (53) 3275-7137. E-mail: amaurisanto@hotmail.com

3 EE/U FRGS, Rua Sarmento Leite, 425, CEP 90050-170, Porto Alegre, RS. Fone: (51) 3316-3567. E-mail: vbatista@mecanica.ufrgs.br
} 


\section{INTRODUÇÃO}

Com o deslocamento das ferramentas de mobilização através do solo, ocorrem diversas interações, decorrentes do atrito entre esses dois elementos, ocasionando a perda de material por parte do equipamento e, consequientemente, o seu desgaste. Tal interação provoca alterações nas características geométricas das ferramentas as quais refletirão em maior esforço de tração e dificuldade na execução do trabalho, de forma adequada.

Embora existam diversos estudos sobre a demanda de tração, pouca importância tem sido dada ao desgaste de ferramentas simétricas de mobilização do solo (ponteiras de sulcadores de semeadoras, de escarificadores e de subsoladores), como os trabalhos de Mourad \& Santos (2003), que construíram um equipamento para a avaliação do desgaste de ferramentas, em função do tipo de solo em condição de laboratório e Espírito Santo (2005) que avaliou, em condições de campo, o desgaste de dois materiais de ponteiras de sulcadores de adubo de semadoras de plantio direto.

Entre as diversas formas de desgaste, o principal, encontrado na operação de mobilização do solo, é o desgaste por abrasão, que se constitui na remoção do material da ferramenta devido ao atrito com as partículas do solo. De acordo com Mesquita \& Barbosa (2005), o fim da vida das ferramentas normalmente condiciona-se ao desgaste, devido as altas tensões de contato, associadas ao deslizamento relativo da ferramenta, podendo o processo conter partículas de alta dureza na região de deslizamento, causando desgaste por abrasão. Segundo Bhole \& Yu (1992), o desgaste abrasivo é o que melhor descreve a remoção de material de uma superfície sólida pela ação do solo.

Barros \& Melo (2008), consideram o desgaste abrasivo como sendo aquele que ocorre entre superfícies móveis em contato, sob atuação de uma carga, onde a presença de protuberâncias duras nos corpos ou partículas duras no meio, promovem interações físicas que deformam a superfície podendo levar a remoção de material das superfícies.

A fricção entre duas superfícies rugosas provoca a retirada de material da mais macia sem sua posterior adesão, à outra superfície de maior dureza. Segundo Reis \& Forcellini (2002), as ponteiras sulcadoras, por representarem as partes ativas dos equipamentos de preparo do solo, são responsáveis diretas por sua mobilização sujeitas, portanto, ao desgaste por abrasão, como conseqüência com o transcorrer das operações de campo, apresentam modificações em sua configuração geométrica, podendo comprometer o formato do sulco.

As características de fricção do solo no aço influenciam o desempenho dos equipamentos, de três maneiras: primeiro, o desgaste se constitui em um problema, tanto no equipamento de preparo do solo como no cultivo devido à natureza abrasiva de muitos solos (Richardson, 1967); em segundo lugar, a força exigida para separar ou mover o solo não só depende das propriedades físicas do solo mas, também, do atrito solo/equipamento (Hettiaratchi et al., 1966); finalmente, a magnitude do atrito de natureza interna do solo estabelece o grau de abrasividade do solo na interface (Stafford \& Tanner, 1977).
O desgaste de uma ferramenta que atua diretamente no solo, depende de vários fatores, entre eles os atributos do solo e características da ferramenta. Segundo Owsiak, (1997), o desgaste de uma ferramenta de corte do solo está à mercê das condições do solo, dos fatores operacionais e das características da ferramenta; salienta, ainda, que na prática da pesquisa é muito difícil cobrir simultaneamente todos os fatores de influência sendo que, geralmente, apenas os efeitos de alguns fatores são investigados.

De acordo com Fernandes et al. (2002), o estudo dos mecanismos de desgaste dos materiais utilizados em implementos agrícolas é fundamental para a otimização na escolha dos mesmos e para a previsão da durabilidade de um equipamento. Ponteiras projetadas inadequadamente são levadas a substituições excessivas; este procedimento se torna dispendioso pois, além da quantidade de ferramentas utilizadas, demanda em tempo de reposição, que poderia ser utilizado em trabalho efetivo (Espírito Santo, 2005).

Estudos realizados por Espírito Santo (2005) mostraram que em solo franco-arenoso ponteiras de hastes sulcadoras de adubo de semeadoras de plantio direto apresentaram elevados índices de desgaste, sendo sua vida útil máxima estimada em torno de dez horas de trabalho. O mesmo autor verificou que, quanto maior o desgaste da ponteira, maior também a força horizontal requerida por esta ferramenta e, consequentemente, mais energia deve ser imposta à tração do equipamento.

Bobobee et al (2006), desenvolveram trabalho referente a determinação do rápido desgaste de cultivadores de tração animal nos solos de Gana, onde verificaram que os principais fatores que afetam a taxa de desgaste são a quantidade de areia e umidade. Concluíram que solos com maior teor de areia proporcionam maiores desgastes nas ferramentas. Fator também identificado por Espírito Santo (2005) e Bolzani et al. (2007).

Segundo Trevisan (2007), a textura e o teor de água do solo são fatores que influenciam na taxa de desgaste dos órgãos ativos. O aumento do teor de água em solos argilosos diminui a taxa de desgaste, enquanto que em arenosos aumenta.

A possibilidade de se fazer a correta avaliação e previsão da durabilidade de mecanismos que atuam no rompimento do solo, são fatores significativos e decisivos na análise dos equipamentos agrícolas (Owsiak, 1997). A taxa de desgaste, das ferramentas de mobilização do solo normalmente é determinada através da perda de massa; entretanto, com a análise da variação de sua configuração geométrica, torna-se possível correlacionar e comparar a ação abrasiva do solo sobre sua geometria e a influência desta variação no seu desempenho.

A variação da configuração geométrica de ferramentas simétricas de mobilização do solo ocorrida em função do processo abrasivo quando de sua interação com o solo, pode ser descrita de forma bastante rápida e precisa, através da utilização da fotografia digital; portanto, o objetivo do trabalho foi propor e testar uma nova metodologia baseada na utilização da fotografia digital para verificação do desgaste de ferramentas simétricas de mobilização do solo possibilitando 
a observação da variação geométrica da ferramenta.

\section{MATERIAL E MÉTODOS}

A fim de se obter o desgaste das ferramentas, executaramse atividades de campo na área da Faculdade de Veterinária da Universidade Federal de Pelotas, município de Capão do Leão, RS, Brasil, latitude $31^{\circ} 52^{\prime} 00^{\prime \prime}$ sul, e longitude $52^{\circ} 21^{\prime} 24^{\prime \prime}$ oeste, local em que o solo, pertencente à unidade de mapeamento Pelotas, é denominado Planossolo Hidromórfico (Streck et al., 1999). Coletaram-se amostras de solo no total de 14, para se quantificar o seu teor de água e caracterizar sua textura no momento da execução dos testes.

Para uma caracterização melhor do solo, também se executaram análises referentes à sua resistência a penetração, ao longo do perfil, até $42 \mathrm{~cm}$ de profundidade, obtendo-se os dados apresentados na Tabela 1.

Observa-se, na etapa 2 que, entre 25.000 e $40.000 \mathrm{~m}$, o solo, a $12 \mathrm{~cm}$ de profundidade, se encontrava bem mais compactado do que no restante do experimento apresentando resistência a penetração média, de $3,48 \mathrm{MPa}$, bem acima daquela observada nas etapas 1 e 3; 2,05 $\mathrm{MPa}$ e 2,93 MPa, respectivamente.

Tabela 1. Resistência do solo à penetração, em $\mathrm{MPa}$, nas diferentes etapas de trabalho*

\begin{tabular}{cccc}
\hline \multirow{3}{*}{ Profundidade (cm) } & \multicolumn{3}{c}{ Etapas de trabalho } \\
\cline { 2 - 4 } 0 & $\mathbf{1}$ & $\mathbf{2}$ & $\mathbf{3}$ \\
3 & 0,00 & 0,00 & 0,00 \\
6 & 0,69 & 1,40 & 1,89 \\
9 & 1,38 & 2,80 & 2,99 \\
12 & 1,88 & 3,22 & 3,04 \\
15 & 2,05 & 3,48 & 2,93 \\
18 & 2,41 & 3,05 & 3,04 \\
21 & 2,86 & 2,94 & 3,22 \\
24 & 2,58 & 3,24 & 2,99 \\
27 & 2,69 & 3,08 & 3,62 \\
30 & 2,95 & 2,58 & 3,66 \\
33 & 3,19 & 2,68 & 2,49 \\
36 & 2,80 & 2,22 & 2,12 \\
39 & 2,94 & 2,07 & 2,02 \\
42 & 2,40 & 2,04 & 1,98 \\
\hline
\end{tabular}

* Etapa 1 de 2.500 a 20.000 m lineares. Etapa 2 de 25.000 a 40.000 m lineares. Etapa 3 de 45.000 a $60.000 \mathrm{~m}$ lineares. Valores médios referentes a observações

Como ferramenta simétrica de mobilização do solo, utilizaram-se ponteiras de hastes sulcadoras de adubo (Figura 1) de uma semeadora para plantio direto, a qual se compunha de nove linhas espaçadas $0,45 \mathrm{~m}$ cada uma, e se selecionaram quatro linhas da máquina, com ponteiras confeccionadas em aço SAE 1060 - forjado, tendo-se então os resultados médios de desgaste de quatro corpos de prova.

Com vistas ao desgaste nas ponteiras, trabalhou-se com as mesmas a uma profundidade média de $0,12 \mathrm{~m}$ durante $12 \mathrm{~h}$. As etapas para a retirada das ponteiras e análise de sua área frontal, lateral e pesagem, foram posteriores à primeira

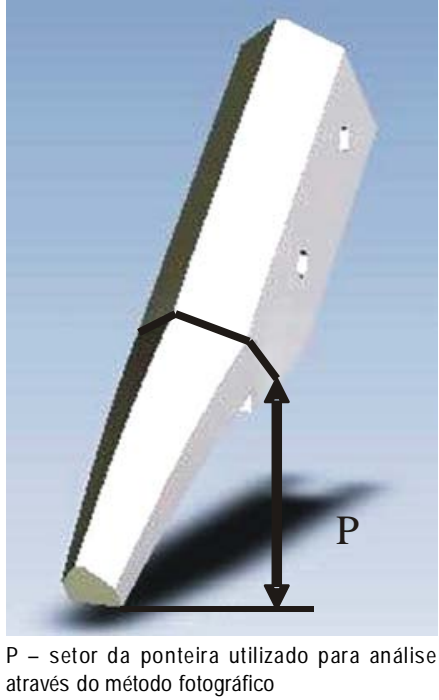

Figura 1. Ponteira utilizada no estudo

meia hora de trabalho, após a primeira hora de trabalho e de hora em hora trabalhada, até se atingir a décima segunda hora. A velocidade de trabalho utilizada foi de $5 \mathrm{~km} \mathrm{~h}^{-1}$; portanto, cada período trabalhado (hora), correspondeu a um percurso de $5.000 \mathrm{~m}$ lineares.

Após cada percurso as ponteiras foram retiradas das hastes procedendo-se à sua limpeza, para eliminação de qualquer vestígio de solo ou outro material; posterior à limpeza, as ponteiras foram pesadas em balança digital com resolução de centésimos de grama sendo então colocadas sobre uma base com escala milimetrada no fundo e fotografadas com câmera fotográfica digital com 2,1 Mpixel de resolução, a fim de se quantificar sua variação geométrica. Através das fotografias e se utilizando um programa de CAD (computer aided design), fez-se o desenho das ferramentas desgastadas obtendo-se, assim, a variação geométrica das ponteiras e a área frontal e lateral remanescente a cada período trabalhado. Com os resultados desta variação geométrica (perda de área), por período trabalhado, calculou-se a perda percentual relativa à área lateral e frontal de cada ferramenta. Os dados assim obtidos foram analisados por análise de variância, segundo um delineamento completamente casualizado com quatro repetições (ponteiras) e teste de comparação de médias de Tukey $(\mathrm{P} \leq 0,01)$.

\section{RESULTADOS E DISCUSSÃO}

Obtiveram-se, com relação ao solo utilizado, os valores médios de $0,77 \mathrm{~kg} \mathrm{~kg}^{-1}$ de areia, $0,15 \mathrm{~kg} \mathrm{~kg}^{-1}$ de silte e $0,08 \mathrm{~kg} \mathrm{~kg}^{-1}$ de argila caracterizando-o, desta forma, quanto à sua granulometria como franco-arenoso. $\mathrm{O}$ teor de água médio do solo durante os trabalhos, foi de $0,13 \mathrm{~kg} \mathrm{~kg}^{-1}$, distinguindo-se seu estado como friável.

$\mathrm{Na}$ Tabela 2 se apresentam os dados referentes à evolução do desgaste de quatro corpos de prova, através da utilização do método convencional de análise de desgaste, ou seja, através da perda de massa da ferramenta. 
Tabela 2. Evolução da perda de massa, e desgaste acumulado percentual das ponteiras construídas em Aço SAE 1060 forjado, por

\begin{tabular}{|c|c|c|c|c|c|c|c|c|c|c|}
\hline \multirow{3}{*}{$\begin{array}{l}\text { etapa de } \\
\text { Etapa } \\
\text { (m) }\end{array}$} & \multicolumn{10}{|c|}{ Ponteiras de aço SAE 1060 , forjado } \\
\hline & \multicolumn{2}{|c|}{ S1 } & \multicolumn{2}{|c|}{ S2 } & \multicolumn{2}{|c|}{ S3 } & \multicolumn{2}{|c|}{ S4 } & \multicolumn{2}{|c|}{ Média } \\
\hline & (g) & $(\%)$ & (g) & $(\%)$ & (g) & $(\%)$ & (g) & $(\%)$ & (g) & $(\%)$ \\
\hline 0 & 0,00 & 0,00 & 0,00 & 0,00 & 0,00 & 0,00 & 0,00 & 0,00 & 0,00 & 0,00 \\
\hline 2.500 & 5,71 & 1,52 & 7,42 & 1,83 & 8,16 & 2,12 & 8,36 & 2,20 & 7,41 & 1,92 \\
\hline 5.000 & 10,57 & 2,81 & 13,77 & 3,40 & 15,21 & 3,95 & 15,66 & 4,12 & 13,80 & 3,57 \\
\hline 10.000 & 26,01 & 6,91 & 25,98 & 6,41 & 30,59 & 7,94 & 28,80 & 7,58 & 27,85 & 7,21 \\
\hline 15.000 & 37,64 & 10,00 & 38,20 & 9,42 & 44,82 & 11,63 & 40,96 & 10,78 & 40,41 & 10,46 \\
\hline 20.000 & 50,79 & 13,49 & 49,84 & 12,30 & 55,51 & 14,40 & 51,67 & 13,60 & 51,95 & 13,45 \\
\hline 25.000 & 66,26 & 17,60 & 63,67 & 15,71 & 71,60 & 18,58 & 67,74 & 17,82 & 67,32 & 17,43 \\
\hline 30.000 & 90,11 & 23,93 & 81,94 & 20,22 & 92,71 & 24,06 & 88,31 & 23,24 & 88,27 & 22,86 \\
\hline 35.000 & 111,39 & 29,58 & 98,97 & 24,42 & 112,93 & 29,30 & 112,41 & 29,58 & 108,93 & 28,22 \\
\hline 40.000 & 137,65 & 36,56 & 123,36 & 30,44 & 131,67 & 34,17 & 136,84 & 36,01 & 132,38 & 34,29 \\
\hline 45.000 & 159,07 & 42,25 & 142,00 & 35,03 & 150,23 & 38,98 & 159,00 & 41,84 & 152,58 & 39,53 \\
\hline 50.000 & 178,51 & 47,41 & 158,37 & 39,07 & 171,80 & 44,58 & 176,63 & 46,48 & 171,33 & 44,39 \\
\hline 55.000 & 210,57 & 56,79 & 181,91 & 45,72 & 195,10 & 51,72 & 202,23 & 54,41 & 197,45 & 52,16 \\
\hline 60.000 & 235,79 & 62,63 & 204,42 & 50,44 & 221,04 & 57,36 & 230,21 & 60,57 & 222,87 & 57,75 \\
\hline
\end{tabular}

Os dados referentes à evolução do desgaste de quatro corpos de prova por etapa trabalhada relativa à área frontal e lateral, utilizando-se o método da fotografia digital, se encontram nas Tabelas 3 e 4.

Com os valores médios das Tabelas 2 a 3 , confeccionou- se a Tabela 4; na qual se encontram a evolução do percentual médio de desgaste das ferramentas e respectivas diferenças estatísticas por etapa de trabalho, concernente a área frontal e lateral das ponteiras e média final de desgaste para o método da fotografia digital (método fotográfico), bem como

Tabela 3. Evolução da perda de área, em $\mathrm{mm}^{2}$, e desgaste percentual frontal (A) e lateral (B), acumulado, por etapa de trabalho, das ponteiras construídas em Aço SAE 1060, forjado - método fotográfico

\begin{tabular}{|c|c|c|c|c|c|c|c|c|c|c|}
\hline \multirow{3}{*}{$\begin{array}{l}\text { Etapa } \\
\text { (m) }\end{array}$} & \multicolumn{10}{|c|}{ Ponteiras de aço SAE 1060 , forjado } \\
\hline & \multicolumn{2}{|c|}{ S1 } & \multicolumn{2}{|c|}{ S2 } & \multicolumn{2}{|c|}{ S3 } & \multicolumn{2}{|c|}{ S4 } & \multicolumn{2}{|c|}{ Média } \\
\hline & $\left(\mathrm{mm}^{2}\right)$ & $(\%)$ & $\left(\mathrm{mm}^{2}\right)$ & $(\%)$ & $\left(\mathrm{mm}^{2}\right)$ & $(\%)$ & $\left(\mathrm{mm}^{2}\right)$ & $(\%)$ & $\left(\mathrm{mm}^{2}\right)$ & $(\%)$ \\
\hline \multicolumn{11}{|c|}{ A Frontal } \\
\hline 0 & 1175,82 & 0,00 & 1198,95 & 0,00 & 1156,98 & 0,00 & 1157,05 & 0,00 & 1172,20 & 0,00 \\
\hline 2.500 & 1129,4 & 3,95 & 1149,28 & 4,14 & 1125,03 & 2,76 & 1122,22 & 3,01 & 1131,48 & 3,47 \\
\hline 5.000 & 1065,77 & 9,36 & 1102,09 & 8,08 & 1065,01 & 7,95 & 1082,36 & 6,46 & 1078,81 & 7,97 \\
\hline 10.000 & 1045,81 & 11,06 & 1067,36 & 10,98 & 1005,83 & 13,06 & 1016,53 & 12,14 & 1033,88 & 11,80 \\
\hline 15.000 & 999,17 & 15,02 & 966,65 & 19,38 & 949,50 & 17,93 & 959,63 & 17,06 & 968,74 & 17,36 \\
\hline 20.000 & 938,88 & 20,15 & 930,77 & 22,37 & 892,76 & 22,84 & 916,10 & 20,82 & 919,63 & 21,55 \\
\hline 25.000 & 871,52 & 25,88 & 890,21 & 25,75 & 890,63 & 23,02 & 879,02 & 24,03 & 882,85 & 24,68 \\
\hline 30.000 & 768,59 & 34,63 & 808,75 & 32,55 & 779,87 & 32,59 & 813,32 & 29,71 & 792,63 & 32,38 \\
\hline 35.000 & 731,09 & 37,82 & 757,28 & 36,84 & 746,95 & 35,44 & 741,09 & 35,95 & 744,10 & 36,52 \\
\hline 40.000 & 637,75 & 45,76 & 681,50 & 43,16 & 670,45 & 42,05 & 689,56 & 40,40 & 669,82 & 42,86 \\
\hline 45.000 & 569,12 & 51,60 & 639,13 & 46,69 & 607,31 & 47,51 & 602,64 & 47,92 & 604,55 & 48,43 \\
\hline 50.000 & 503,30 & 57,20 & 603,90 & 49,63 & 534,71 & 53,78 & 573,37 & 50,45 & 553,82 & 52,75 \\
\hline 55.000 & 354,71 & 69,83 & 495,20 & 58,70 & 411,05 & 64,47 & 461,84 & 60,08 & 430,70 & 63,26 \\
\hline 60.000 & 303,83 & 74,16 & 449,51 & 62,51 & 352,40 & 69,54 & 398,06 & 65,60 & 375,95 & 67,93 \\
\hline \multicolumn{11}{|c|}{ B Lateral } \\
\hline 0 & 1478,26 & 0,00 & 1489,97 & 0,00 & 1467,66 & 0,00 & 1424,35 & 0,00 & 1465,06 & 0,00 \\
\hline 2.500 & 1426,53 & 3,50 & 1319,37 & 3,71 & 1398,51 & 4,71 & 1341,89 & 5,79 & 1400,40 & 4,41 \\
\hline 5.000 & 1393,14 & 5,76 & 1387,89 & 6,85 & 1335,62 & 9,00 & 1300,19 & 8,72 & 1354,20 & 7,57 \\
\hline 10.000 & 1327,75 & 10,18 & 1328,37 & 10,85 & 1319,53 & 10,09 & 1295,80 & 9,03 & 1317,86 & 10,05 \\
\hline 15.000 & 1308,51 & 11,48 & 1311,66 & 11,97 & 1265,24 & 13,79 & 1271,84 & 10,71 & 1289,31 & 12,00 \\
\hline 20.000 & 1231,84 & 16,67 & 1280,15 & 14,08 & 1240,80 & 15,46 & 1235,08 & 13,29 & 1246,97 & 14,89 \\
\hline 25.000 & 1115,75 & 24,52 & 1145,71 & 23,11 & 1180,22 & 19,58 & 1104,67 & 22,44 & 1136,59 & 22,42 \\
\hline 30.000 & 952,76 & 35,55 & 1020,34 & 31,52 & 1014,50 & 30,88 & 1032,25 & 27,53 & 1004,96 & 31,40 \\
\hline 35.000 & 921,11 & 37,69 & 967,87 & 35,04 & 989,34 & 32,59 & 971,35 & 31,80 & 962,42 & 34,31 \\
\hline 40.000 & 839,68 & 43,20 & 899,80 & 39,61 & 954,50 & 34,96 & 921,52 & 35,30 & 903,88 & 38,30 \\
\hline 45.000 & 792,58 & 46,39 & 864,14 & 42,00 & 871,07 & 40,65 & 862,23 & 39,47 & 847,50 & 42,15 \\
\hline 50.000 & 762,01 & 48,45 & 818,45 & 45,07 & 806,67 & 45,04 & 777,91 & 45,38 & 791,26 & 45,99 \\
\hline 55.000 & 696,37 & 52,89 & 789,28 & 47,03 & 763,20 & 48,00 & 740,91 & 47,98 & 747,44 & 48,98 \\
\hline 60.000 & 560,42 & 62,09 & 758,53 & 49,09 & 667,17 & 54,54 & 664,63 & 53,34 & 662,69 & 54,77 \\
\hline
\end{tabular}


Tabela 4. Evolução da perda percentual e valores médios*

\begin{tabular}{rccc}
\hline Etapa (m) & $\begin{array}{c}\text { Frontal } \\
\text { (Fotográfico) }\end{array}$ & $\begin{array}{c}\text { Lateral } \\
\text { (Fotográfico) }\end{array}$ & $\begin{array}{c}\text { Convencional } \\
\text { (massa) }\end{array}$ \\
0 & 0,00 & 0,00 & 0,00 \\
2.500 & $3,47 \mathrm{~A}$ & $4,41 \mathrm{~A}$ & $1,92 \mathrm{~A}$ \\
5.000 & $7,97 \mathrm{~A}$ & $7,57 \mathrm{~A}$ & $3,57 \mathrm{~A}$ \\
10.000 & $11,81 \mathrm{~A}$ & $10,05 \mathrm{~A}$ & $7,21 \mathrm{~A}$ \\
15.000 & $17,36 \mathrm{~A}$ & $12,00 \mathrm{AB}$ & $10,46 \mathrm{~B}$ \\
20.000 & $21,55 \mathrm{~A}$ & $14,89 \mathrm{~B}$ & $13,45 \mathrm{~B}$ \\
25.000 & $24,68 \mathrm{~A}$ & $22,42 \mathrm{AB}$ & $17,43 \mathrm{~B}$ \\
30.000 & $32,38 \mathrm{~A}$ & $31,40 \mathrm{~A}$ & $22,86 \mathrm{~B}$ \\
35.000 & $36,52 \mathrm{~A}$ & $34,31 \mathrm{~A}$ & $28,22 \mathrm{~B}$ \\
40.000 & $42,86 \mathrm{~A}$ & $38,30 \mathrm{AB}$ & $34,29 \mathrm{~B}$ \\
45.000 & $48,43 \mathrm{~A}$ & $42,15 \mathrm{~B}$ & $39,53 \mathrm{~B}$ \\
50.000 & $52,75 \mathrm{~A}$ & $45,99 \mathrm{~B}$ & $44,39 \mathrm{~B}$ \\
55.000 & $63,26 \mathrm{~A}$ & $48,98 \mathrm{BC}$ & $52,16 \mathrm{C}$ \\
60.000 & $67,93 \mathrm{~A}$ & $54,77 \mathrm{BC}$ & $57,75 \mathrm{C}$ \\
\hline
\end{tabular}

Médias seguidas de mesma letra na linha não diferem significativamente pelo teste de Tukey $(P \leq 0,01)$

* referentes às áreas frontal e lateral (fotográfico) e massa (convencional) por etapa de trabalho

para o método convencional (perda de massa); a análise da variância desses dados identificou interação entre o método de determinação e a etapa de desgaste $(P=0,00009)$, fato que levou as diferenças entre os métodos ao longo das etapas; o coeficiente de variação foi de $8,91 \%$ demonstrando elevada precisão no experimento.

Observa-se, através das Tabelas 2 a 3, que a vida útil estimada para as ponteiras foi em torno de $55.000 \mathrm{~m}$ lineares (11 h), quando são analisadas pelo método da perda de massa e de $50.000 \mathrm{~m}$ lineares $(10 \mathrm{~h}$ ) quando se utiliza a média obtida para os desgastes frontal e lateral, pelo método da fotografia digital; a partir desses períodos, as ferramentas passam a apresentar uma perda de massa e/ou área igual ou superior a $50 \%$ da inicial. A análise do formato do sulco em conjunto com a mobilização de solo, proporcionada pela ferramenta quando a mesma apresenta perda de $50 \%$ de sua massa e/ou área, permite considerar que com esta nova geometria ela não mais é capaz de cumprir adequadamente sua função. Normalmente, a jornada de trabalho diária para máquinas agrícolas, se situa em torno de 10 h; por esta análise inicial se infere que, nessas condições de trabalho, seria necessário proceder-se a uma troca diária do conjunto de ponteiras sulcadoras da semeadora, o que denota um problema a ser resolvido.

Verifica-se, por meio da Tabela 4, que em etapas iniciais de trabalho (até os primeiros $10.000 \mathrm{~m}$ ) a evolução do desgaste da ferramenta pode ser quantificada por qualquer um dos métodos testados, chegando-se aos mesmos resultados; entretanto, quando começa a ocorrer um desgaste mais acentuado, os métodos passam a diferir.

A análise do desgaste em que se utilizou o método fotográfico para a porção frontal da ferramenta detectou valores superiores àqueles obtidos quando do uso do método convencional (análise de desgaste por perda de massa), a partir da etapa de $15.000 \mathrm{~m}$; tal fato pode ser explicado em função de que no método convencional se leva em conta a totalidade da estrutura da ponteira (todo o corpo da ferramenta), enquanto no método fotográfico a análise do desgaste se atém apenas à porção referente à sua parte ativa, ou seja, a ponta (setor P, Figura 1), a qual traduz, de forma mais detalhada, onde e como este ocorre.

Conforme pôde ser observado na Tabela 1, entre as etapas de 25.000 a $40.000 \mathrm{~m}$ o solo se encontrava bem mais compactado que no restante do experimento, fato que levou a um desgaste mais acentuado na parte frontal da ponteira; em tais condições (solo duro) o método fotográfico foi capaz de registrar, de forma mais verossímil, o fenômeno do desgaste, pois desconsidera as porções da ponteira que não estão diretamente envolvidas na mobilização do solo, ao contrário do método convencional.

Desta forma se considera o método aqui proposto mais preciso e eficiente, em função de permitir não só a verificação do desgaste acumulado que ocorre na ferramenta mas, também, a possibilidade de se constatar a variação geométrica da ponteira e, desta forma, a identificação de zonas mais sujeitas ao desgaste, as quais podem ser melhor estudadas posteriormente, no sentido de se buscar alternativas que permitam o prolongamento da vida útil da ferramenta; como ilustração a este último se apresenta a Figura 2, a seguir, na qual se observa a variação geométrica ocorrida na ponteira tanto, na sua porção frontal quanto na lateral, em três distintas etapas de trabalho; entretanto, o método fotográfico para a porção lateral da ferramenta apresentou grande variação de resultados ao longo das etapas sendo, então, considerado inadequado à correta determinação do percentual de desgaste da ponteira, porém a visualização por etapa de trabalho das fotografias da porção lateral da ferramenta (Figura 2B) permite identificar como e onde ocorre a evolução do desgaste, contribuindo para uma análise mais precisa deste fenômeno, além de permitir, também, a determinação da variação da geometria da ferramenta, principalmente de seu ângulo de ataque, sempre que o desgaste vai ocorrendo.

Outra característica positiva do método proposto é que ele

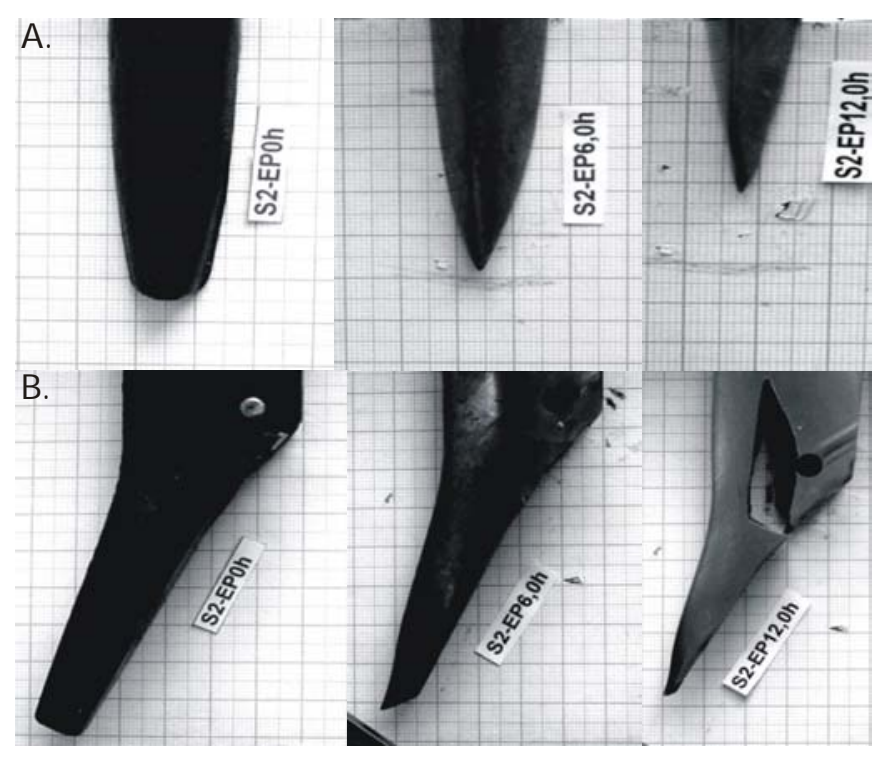

Figura 2. Fotografias frontais (A) e laterais (B) obtidas em algumas etapas de trabalho $(0,30.000,60.000$ m lineares) para uma das ferramentas utilizadas 
torna possível a análise do desgaste das ponteiras sem a necessidade de desmontá-las das hastes sulcadoras; para isto, basta construir um gabarito com escala milimetrada ao fundo e posicioná-lo junto à ponteira, no momento da foto; assim, os experimentos de análise de desgaste de ferramentas simétricas de mobilização do solo se tornarão mais rápidos, visto que a parte mais trabalhosa do método será a obtenção da área, por meio de desenho de sua superficie, a partir da fotografia digital dentro do software de CAD, tratando-se de uma tarefa de fácil e rápida execução.

\section{CONCLUSÕES}

1. O método da fotografia, além de ser rápido, é de fácil execução, tendo-se mostrado bastante preciso, quando comparado com o método convencional.

2. A metodologia proposta possibilita mais facilmente o entendimento de como e onde ocorre o fenômeno de abrasão da ferramenta.

\section{AGRADECIMENTOS}

À Pós-Graduação em Engenharia Rural (PGER) da FAEMUFPel; ao Curso de Especialização em Gerenciamento e Utilização de Máquinas Agrícolas e ao Grupo de Projeto, Fabricação e Automação Industrial (GPFAI) da UFRGS, pela cedência de equipamentos e apoio financeiro; ao Conselho Nacional de Desenvolvimento Científico e Tecnológico (CNPq) pela concessão da bolsa de iniciação científica.

\section{LITERATURA CITADA}

Barros, M. B.; de Mello, J. D. B. Efeito dos parâmetros de teste sobre o mecanismo de desgaste predominante em ensaios de desgaste abrasivo. Revista Horizonte Científico, v.1,n.6, p.1-22, 2006.

Bhole, S.D.; Yu, H. Abrasive wear evaluation of tillage tool materials. Lubrication Engineering, v.48, n.12, p.925-34, 1992.
Bobobee, E.Y. H.;Sraku-Lartyey K.; Fialor, S. C.; Canaco, E. A.; Agodzo, S. K.; Yawson, A.; Gebresenbet, G. Wear rate of animal-draw ploughshares in selected Ghanaian soils. Soil \& Tillage Research, v.93, p.299-308, 2007.

Bolzani, A.; Colet, M. J.; Bejarano, J. M. Z;Sverzut, C. B. Avaliação do desgaste de ponteiras de escarificador pela abrasão do solo. In: Congresso Brasileiro de Engenharia Agrícola, 36, 2007, Bonito. Anais... Bonito: SBEA, 2007. CD Rom.

Espírito Santo, A. C. Desgaste de ponteiras de hastes sulcadoras de semeadoras de plantio direto e sua influência no esforço de tração. Porto Alegre: UFRGS, 2005. 152p. Tese Doutorado

Fernandes, J. C.; Santos, J. E. G.; Santos Filho, A. G.; Bormio, M. R. Avaliação do desgaste de implementos agrícolas para diversos tipos de solos. In: Congresso Brasileiro de Engenharia Agrícola, 31, 2002, Salvador. Anais... Salvador: SBEA, 2002. CD Rom.

Hettiaratchi, D.R.P.; Witney, B.D.; Reece, A.R. The calculation of passive pressure in two-dimensional soil failure. Journal of Agricultural Engineering Research, v.11, p.89-107, 1966.

Mesquita, R. A.; Barbosa, C. A. Uma avaliação das propriedades de desgaste e tenacidade em aços para trabalho a frio. Tecnologia em Metalurgia e Materiais, v.2, n.2, p.12-18, 2005.

Mourad, R. B. A.; Santos, J. E. G. dos. Projeto e construção de bancada para verificação do desgaste dos órgãos ativos de implementos agrícolas submetidos à abrasão em quatro tipos de solos. Engenharia Agrícola, v.23 n.3, p.547-555, 2003.

Owsiak, Z. Wear of symmetrical wedge-shaped tillage tools. Soil Tillage Research, v.50, p.295-308, 1997.

Reis, A.V.; Forcellini, F. A. Seleção de materiais para ponteiras de escarificadores. Engenharia Agrícola, v.22, p.270-277, 2002.

Richardson, R.C.D. The wear of metallic materials by soil. Journal of Agricultural Engineering Research, v.12, p.22-39. 1967.

Stafford, J. V.; Tanner, D. W.; The frictional characteristics of a steel sliding on soil. Europe Journal of Soil Science, v.28, n.4, p-541-553, 1977.

Streck, E.V.; Kampf, N.; Klamt, E. Atualização da classificação taxionômica das unidades de mapeamento do levantamento de reconhecimento dos solos do estado do Rio Grande do Sul. Porto Alegre: EMATER, 1999. 5p. Informativo EMATER-RS, n.9

Trevisan, C. Desgaste de órgãos ativos de máquinas e implementos agrícolas de preparo do solo: avaliação bibliográfica. Piracicaba: ESALQ, 2007. 74p. Dissertação Mestrado 